
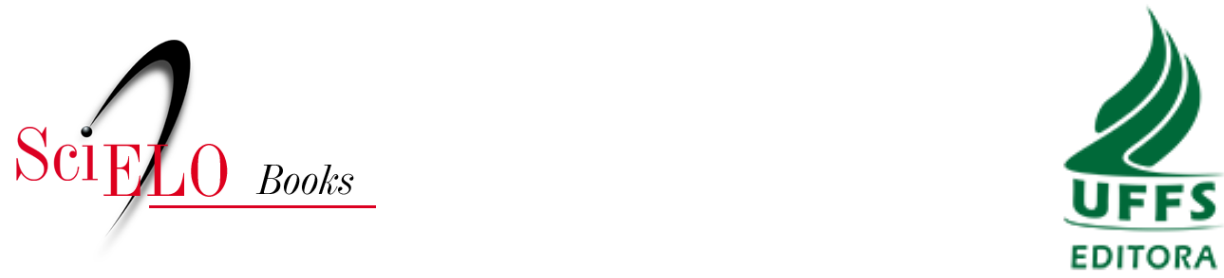

\title{
Parte VII - Desenvolvimento e políticas públicas Capítulo 3 - As políticas públicas e o ensino superior no Brasil: o campus Cerro Largo da Universidade Federal da Fronteira Sul
}

\author{
Reneo Pedro Prediger \\ Dieter Rugard Siedenberg \\ Dilson Trennepohl \\ Roseli Fistarol Krüger \\ Sérgio Luís Allebrandt
}

\section{SciELO Books / SciELO Livros / SciELO Libros}

PREDIGER, R.P., SIEDENBERG, D.R., TRENNEPOHL, D., KRÜGER, R.F., and ALLEBRANDT, S.L. As políticas públicas e o ensino superior no Brasil: o campus Cerro Largo da Universidade Federal da Fronteira Sul. In: ROTTA, E., LAGO, I.C., JUSTEN, A.F., and SANTOS, M., eds. Conhecimento em rede: desenvolvimento, cooperação e integração regional em território de fronteira - Rede CIDIR: 10 anos [online]. Chapecó, SC: Editora UFFS, 2019, pp. 469486. ISBN: 978-65-5019-011-8.

https://doi.org/10.7476/9786586545432.0028.

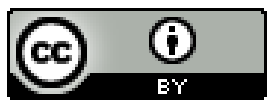

All the contents of this work, except where otherwise noted, is licensed under a Creative Commons Attribution 4.0 International license.

Todo o conteúdo deste trabalho, exceto quando houver ressalva, é publicado sob a licença Creative Commons Atribição 4.0. 


\title{
AS POLÍTICAS PÚBLICAS E O ENSINO SUPERIOR NO BRASIL: O CAMPUS CERRO LARGO DA UNIVERSIDADE FEDERAL DA FRONTEIRA SUL
}

\author{
Reneo Pedro Prediger ${ }^{1}$ \\ Dieter Rugard Siedenberg ${ }^{2}$ \\ Dilson Trennepohl ${ }^{3}$ \\ Roseli Fistarol Krüger ${ }^{4}$ \\ Sérgio Luís Allebrandt ${ }^{5}$
}

1 Professor da UFFS - Campus Cerro Largo. Doutorando em Desenvolvimento Regional (PPGDR/ UNIJUÍ)., Bolsista CAPES. Contato: reneo@uffs.edu.br

2 Professor titular do PPGDR/UNIJUÍ. Doutor em Geografia Econômica pela Universitat Tuebingen/ Alemanha (2000). Contato: dieterrs@unijui.edu.br

3 Professor titular do PPGDR/UNIJUÍ. Doutor em Desenvolvimento Regional (UNISC). Contato: dilson@unijui.edu.br

4 Graduada em Administração. Doutoranda em Desenvolvimento Regional PPGDR/UNIJUÍ. Bolsista PROSUP/CAPES. Contato: rfistarol@gmail.com

5 Professor titular do PPGDR/UNIJUÍ. Doutor em Desenvolvimento Regional (UNISC). Contato: allebr@unijui.edu.br 


\section{INTRODUÇÃO}

$\mathrm{Na}$ América Latina, a desigualdade é uma constante. Além das nações serem desiguais entre si, todos os países apresentam diferenças internas entre províncias, estados, regiões, municípios, localidades ou qualquer forma de escala e dimensão que se venha a utilizar. Essa ausência de equilíbrio se manifesta em muitas dimensões, sejam econômicas, sociais, políticas ou institucionais. Como exemplos, podem-se citar a distribuição de renda, o acesso ao mercado de trabalho, o acesso aos serviços de saúde, à segurança e à educação.

O relatório da CEPAL, publicado em 2015, apresenta um panorama do desenvolvimento territorial na América Latina e no Caribe e descreve alguns mecanismos determinantes do desenvolvimento e das desigualdades territoriais. Entre esses mecanismos estão: as diferenças nas estruturas produtivas ocasionadas por esquemas do tipo centro-periferia; a transferência geográfica de receitas das periferias para os principais centros internos ou para o exterior; o processo de migrações seletivas de população jovem e qualificada das periferias para as áreas centrais; e, finalmente, um conjunto de fatores endógenos aos territórios cuja ativação e promoção poderiam gerar processos de crescimento e desenvolvimento (CEPAL, 2015).

A educação, notadamente a de nível superior, constitui-se em um desses fatores que impulsionaram os desequilíbrios regionais. No Brasil, além de ter surgido em momento posterior a muitos dos países sul-americanos, as instituições públicas historicamente apresentaram características centralizadoras e elitistas. Assim, fomentou desigualdades tanto sob o aspecto geográfico, privilegiando regiões com investimentos e recursos públicos, quanto sob o aspecto social, restringindo o acesso de classes sociais ou de grupos específicos da população.

Este capítulo apresenta a evolução do ensino superior público no Brasil e como essas concentrações espaciais ocorreram. Mostra ainda a morosidade do poder público, em qualquer um de seus níveis, em interferir nessas distorções. As políticas públicas, ao menos no século passado, limitaram-se a ações pontuais com a criação de uma ou outra instituição. Políticas públicas voltadas à descentralização das instituições, democratização do acesso e melhoria das condições do sistema federal de ensino superior foram observadas apenas neste século. 
A criação da Universidade Federal da Fronteira Sul (UFFS), no ano de 2009, é uma das ações do governo brasileiro resultante do conjunto de políticas públicas estabelecidas após a vigência do Plano Nacional de Educação, em 2001, e do Plano de Desenvolvimento da Educação, editado em 2007. É objeto deste estudo acompanhar o processo de criação da instituição e observar um de seus campi e a sua sede na cidade de Cerro Largo, a partir de alguns indicadores e informações quantitativas que contextualizem o desenvolvimento local.

\section{A EDUCAÇÃO SUPERIOR NO BRASIL}

No Brasil, como consequência da política portuguesa de evitar a formação de quadros intelectuais nas colônias, o ensino superior surgiu tardiamente. Durante todo o período colonial, enquanto a América Hispânica já apresentava um número considerável de instituições, o Brasil nada construíra em relação ao ensino superior. Apenas em 1808, com o translado da corte portuguesa para o Brasil, houve iniciativas nesse sentido. Embora muitas instituições tenham sido criadas nos primeiros anos da Coroa portuguesa no Brasil, era evidente a ausência de preocupação e interesse com a criação de universidades. O objetivo da época era formar profissionais necessários ao funcionamento do estado ou de interesse das elites locais. Ainda, e de forma diferente das colônias espanholas, também não se transferiu à igreja a responsabilidade dessas atividades (DURHAM, 1998).

Até o final do século XIX, a situação pouco mudou no cenário da educação superior. A expansão foi extremamente lenta e, até a Proclamação da República, em 1889, existiam apenas 24 instituições com as mesmas características iniciais (TEIXEIRA, 1989, apud DURHAM, 1998). Teixeira (1989, apud SAMPAIO, 1991) apresenta treze instituições para o período de 1900 a 1910 e 34 instituições de 1910 a 1920. Embora o incremento no número de instituições e a mudança no perfil das suas mantenedoras, algumas de cunho religioso e também da iniciativa privada, o foco continuava sendo a formação de profissionais liberais em cursos de Direito, Medicina e Engenharia.

A década seguinte, de 1920 a 1930, começa a apresentar um crescimento no incremento do número de instituições. Neste período foram criadas 86 escolas de ensino superior. Começam a surgir, nesta época, as primeiras universidades, 
o que mais uma vez evidencia o atraso brasileiro em relação aos demais países latino-americanos. No Estado Novo, período que vai de 1930 a 1945, são 95 novas instituições (SAMPAIO, 1991).

A redemocratização do país, a partir de 1945 até o final dos anos 50, apresentou o desenvolvimento de um sistema federal de ensino superior. A federalização de algumas universidades estaduais criadas na década de 1930, somada à ênfase de que cada Estado brasileiro deveria ter, pelo menos, uma universidade federal e, até mesmo, a criação da primeira Universidade Católica, fizeram com que 223 instituições de ensino superior fossem criadas (SAMPAIO, 1991). Esse mesmo nível de crescimento, isto é, 375 instituições, verifica-se na década seguinte, pelo menos até o ano de 1968, quando da reforma universitária.

O IBGE (2003) divulga em "Estatísticas do Século XX” informações referentes às instituições de ensino superior, de acordo com sua organização acadêmica e dependência administrativa, a partir do ano de 1971. É possível, a partir do relatório, fazer algumas observações sobre a evolução do ensino superior nesse período. No ano de 2002, por exemplo, são 1.637 instituições, das quais apenas 162 são universidades. Essa proporção é relativamente constante em todos os anos observados. O relatório mostra, também, a quase inexistência de variações no número de instituições no período que inicia em 1975 até o ano de 1998. Um extraordinário avanço, entretanto, pode ser verificado no período seguinte, de 1998 a 2002. O número total de instituições pulou de 973, em 1998, para 1.637 instituições em 2002. A nova Lei de Diretrizes e Bases da Educação Nacional (LDB), aprovada em 1996, em conjunto com as políticas educacionais dos oito anos de governo FHC, pode ter influenciado o surgimento da quase totalidade desses novos estabelecimentos, que pertencem ao setor privado e se constituem em instituições isoladas de ensino superior.

Em 2002, o Brasil possuía 43 universidades federais. Destas, 28 estavam localizadas em capitais estaduais e quinze instaladas em cidades do interior dos estados. Em relação às interioranas, duas instituições estavam localizadas na região Nordeste, dez na região Sudeste e três na região Sul do Brasil, todas no estado do Rio Grande do Sul (RS). Isto é pouco mais do que uma unidade por estado da federação, mesmo considerando as instaladas nas capitais. Fica evidente, dessa forma, a má distribuição desse importante recurso público. As dificuldades de acesso ao ensino superior, dessa forma, iam além do 
reduzido número de vagas comparadas à precária preparação de candidatos de classes sociais e econômicas menos favorecidas. Percebem-se grandes regiões desprovidas de instituições federais de ensino superior e uma significativa parcela da população residente em locais nem sempre muito próxima aos campi dessas universidades.

\section{AS POLÍTICAS PÚBLICAS RECENTES PARA O ENSINO SUPERIOR}

As políticas públicas relacionadas ao ensino superior, neste século, são decorrentes, em parte, do Plano Nacional de Educação de 2001. Dentre os diversos objetivos e metas deste plano constam o estabelecimento de uma política de expansão que diminua as desigualdades de oferta existentes entre diferentes regiões do país e a criação de políticas que facilitem o acesso à educação superior às minorias, vítimas de discriminação. Por outro lado, o Plano de Desenvolvimento da Educação, editado em 2007, complementa o primeiro por meio da intenção de expandir tanto a oferta quanto o acesso ao ensino superior, principalmente na rede pública. Desses planos, e visando tanto ao ensino superior público quanto ao privado, resultaram medidas para a criação de programas de incentivo ao acesso e à permanência do estudante na universidade. Nesse sentido, três grandes programas foram construídos e direcionados às universidades federais, ao ensino profissional e tecnológico e à educação a distância.

O Programa de Reestruturação e Expansão das Universidades Federais (REUNI), estabelecido pelo Decreto no 6.096, de 24 de abril de 2007, no qual o Governo Federal reconhece o papel estratégico das universidades, principalmente as públicas, para o desenvolvimento econômico e social do país, promoveu uma retomada do crescimento do ensino superior público, favorecendo a expansão física, acadêmica e pedagógica das universidades federais.

O segundo é o Programa de Expansão da Educação Superior e Profissional e Tecnológica, que tem como objetivo democratizar o acesso à educação superior e tecnológica, criado pela Lei $\mathrm{n}^{\circ} 11.892$, de 29 de dezembro de 2008 . Este programa foi responsável pela reforma da educação profissional na educação superior, estabelecendo novo formato para a rede federal de educação profissional e tecnológica existente até então no Brasil. 
Finalmente o Programa Universidade Aberta do Brasil (UAB), criado em 2005, contempla a expansão e interiorização da oferta de cursos e programas de educação superior, por meio de parcerias entre as esferas federais, estaduais e municipais do governo (BRASIL, 2016; BRASIL, 2016a).

A expansão da Rede Federal de Educação Superior teve início com a interiorização dos campi das universidades federais. Com isso, o número de municípios atendidos pelas universidades passou de 114, em 2003, para 237, até o final de 2011. Desde o início da expansão, foram criadas quatorze novas universidades e mais de cem novos campi que possibilitaram a ampliação de vagas e a criação de novos cursos de graduação. Também são 38 Institutos Federais, presentes em todos os estados, cada um com diversos campi, oferecendo cursos de qualificação, ensino médio integrado, cursos superiores de tecnologia e licenciaturas. Dados do INEP, do Censo da Educação Superior de 2014, comparados aos de 2002, apontam para um incremento de 121,97\% no número de matrículas neste período. Observa-se também um aumento de $82,9 \%$ no número de funções docentes no intervalo 2003-2014 na rede pública de ensino superior.

Tabela 1 - Instituições de ensino superior por categoria administrativa - Brasil - 2014

\begin{tabular}{l|l|l}
\hline Categoria administrativa & Instituições & $\%$ \\
\hline Pública federal & 107 & 4,52 \\
\hline Pública estadual & 118 & 4,98 \\
\hline Pública municipal & 49 & 2,07 \\
\hline Privada sem fins lucrativos & 1.072 & 45,27 \\
\hline Privada com fins lucrativos & 998 & 42,15 \\
\hline Especial & 24 & 1,01 \\
\hline Total & 2.368 & 100,00 \\
\hline
\end{tabular}

Fonte: Dados do INEP - elaborada pelos autores.

* Encontram-se nessa categoria as instituições oficiais, criadas por lei estadual ou municipal, existentes na data da promulgação da Constituição Federal de 1988, que não sejam total ou preponderantemente mantidas com recursos públicos, portanto, não gratuitas.

Segundo o Censo da Educação Superior, realizado pelo Instituto Nacional de Estudos e Pesquisas Educacionais Anísio Teixeira (INEP), no ano de 2014, o Brasil contava com 2.368 instituições de ensino superior. Elas estão organizadas em diversas categorias administrativas como pode ser observado na Tabela 1. Algumas observações são evidentes. Apenas 12,58\% das instituições de ensino superior no Brasil são mantidas, total ou parcialmente, pelo 
poder público, das quais os estados e municípios respondem pela parcela majoritária. Por outro lado, $87,42 \%$ são de responsabilidade da iniciativa privada.

A Tabela 2 apresenta a distribuição das instituições de acordo com sua organização acadêmica.

Tabela 2 - Instituições de ensino superior por organização acadêmica - Brasil - 2014

\begin{tabular}{l|l|l}
\hline Organização acadêmica & Instituições & $\%$ \\
\hline Universidade & 195 & 8,23 \\
\hline Instituto Federal de Educação, Ciência e Tecnologia & 38 & 1,60 \\
\hline Centro Universitário & 147 & 6,21 \\
\hline Centro Federal de Educação Tecnológica & 2 & 0,08 \\
\hline Faculdade & 1986 & 83,88 \\
\hline Total & 2.368 & \\
\hline
\end{tabular}

Fonte: Dados do INEP - elaborada pelos autores.

É bastante visível que a grande maioria das instituições se dedica unicamente às atividades de ensino. De outro modo, incluindo-se os Institutos Federais, menos de $10 \%$ das instituições, além do ensino, também realizam atividades de pesquisa e extensão. As universidades, por sua vez, correspondem a 8,23\% do total das instituições de ensino superior.

A Tabela 3 mostra as diferentes categorias administrativas que podem ser observadas.

Tabela 3 - Universidades por categoria administrativa - Brasil - 2014

\begin{tabular}{l|l|l}
\hline Categoria administrativa & Universidades & $\%$ \\
\hline Pública federal & 63 & 32,30 \\
\hline Pública estadual & 38 & 19,49 \\
\hline Pública municipal & 1 & 0,51 \\
\hline Privada sem fins lucrativos & 64 & 32,82 \\
\hline Privada com fins lucrativos & 20 & 10,26 \\
\hline Especial $^{*}$ & 9 & 4,62 \\
\hline
\end{tabular}

Fonte: Dados do INEP - elaborada pelos autores.

* Encontram-se nessa categoria as instituições oficiais, criadas por lei estadual ou municipal, existentes na data da promulgação da Constituição Federal de 1988, que não sejam total ou preponderantemente mantidas com recursos públicos, portanto, não gratuitas. 
Nesse recorte das instituições de ensino superior - das universidades - a situação é bastante diferente. Mais da metade, 56,92\%, são instituições públicas. Se forem desconsideradas as instituições privadas sem fins lucrativos - na sua maioria, confessionais e comunitárias - apenas $10,26 \%$ são controladas por pessoas físicas ou grupos empresariais. Assim, quase $90 \%$ das universidades são instituições sem fins lucrativos e se estabeleceram nas suas sedes e campi por motivos diversos que não sejam de ordem financeira.

Desse modo, é conveniente verificar quais são os motivos ou fatores que provocaram essa configuração. São, evidentemente, elementos históricos, mas que são importantes para o entendimento da questão.

\section{A UNIVERSIDADE FEDERAL DA FRONTEIRA SUL (UFFS)}

A Universidade Federal da Fronteira Sul foi criada por meio da Lei n. ${ }^{\circ}$ 12.029, de 15 de setembro de 2009. A sede está localizada no município de Chapecó, em Santa Catarina (SC). A Lei estabelece que a UFFS tenha por objetivo ministrar ensino superior, desenvolver pesquisas e promover a extensão universitária, caracterizando sua inserção regional. A UFFS tem atuação multicampi, abrangendo o norte do Rio Grande do Sul, com campi nos municípios de Cerro Largo, Erechim e Passo Fundo, o oeste de Santa Catarina, com campus em Chapecó, e o sudoeste do Paraná e seu entorno, com campi em Laranjeira do Sul e Realeza (BRASIL, 2009).

A criação da UFFS ocorreu durante a execução do Programa de Apoio ao Plano de Reestruturação e Expansão das Universidades Federais (REUNI). Não faz parte, contudo, das ações previstas para o programa, embora o MEC a considere como sua parte integrante. A UFFS partilha dos princípios de democratização e do objetivo de criar novas universidades no interior do país (COSTA et al., 2011). De acordo com Pereira (2014), a UFFS é produto da mobilização social nos três estados do Sul, aliada à intencionalidade governamental, manifestada em políticas como o REUNI.

A mesorregião Grande Fronteira do Mercosul compreende 396 municípios do norte do Rio Grande do Sul, do oeste de Santa Catarina e do sudoeste 
do Paraná. Essa região possui área total de 139 mil quilômetros quadrados e grau de urbanização relativamente baixo em relação ao restante do País, em torno de $65 \%$, concentrando parcela significativa da população na zona rural (MESOMERCOSUL, 2016). Essa significativa área do Brasil não possuía nenhuma universidade federal. É neste espaço, então, que a UFFS está inserida, sendo para a população dessa região que suas ações e seus programas são prioritariamente direcionados.

Ofereceu, no ano de 2016, 2.022 vagas distribuídas em 45 cursos de graduação. As atividades de pós-graduação são realizadas nos seis campi, tanto lato quanto stricto sensu. Na Pós-Graduação Stricto Sensu são 11 cursos de mestrado, dois doutorados, estes no formato interinstitucional, além de residências médicas e multiprofissionais. Para o atendimento dos 8.656 alunos atualmente matriculados, a UFFS conta com 651 servidores técnico-administrativos e 661 docentes, dos quais 628 em regime de Dedicação Exclusiva (UFFS, 2016).

\section{O CAMPUS CERRO LARGO}

O Campus Cerro Largo conta com 167 servidores, dos quais 96 são docentes e 71 são técnico-administrativos. Dos docentes, 68 têm titulação em nível de Doutorado, enquanto os 28 restantes são mestres, sendo que muitos desses estão realizando seu doutoramento. A tendência é que em um curto espaço de tempo a totalidade dos docentes sejam doutores. Em relação aos servidores técnico-administrativos, treze são mestres, 36 são especialistas, dezesseis possuem curso superior e seis cursaram apenas o ensino médio.

Sete cursos de graduação são ofertados pelo campus Cerro Largo. No turno diurno, os cursos de Administração, Agronomia, Licenciatura em Ciências Biológicas e Engenharia Ambiental. No turno da noite são oferecidos os cursos de Licenciatura em Física, Licenciatura em Química e Letras: Português e Espanhol. A Tabela 4 apresenta o número de alunos matriculados, por curso, no primeiro semestre de 2016. 
Tabela 4 - Alunos matriculados por curso - Campus Cerro Largo - 2016/1

\begin{tabular}{l|l}
\hline Curso & Alunos Matriculados \\
\hline Administração & 193 \\
\hline Agronomia & 274 \\
\hline Ciências Biológicas - Licenciatura & 218 \\
\hline Engenharia Ambiental & 208 \\
\hline Física - Licenciatura & 90 \\
\hline Letras: Português e Espanhol & 136 \\
\hline Química - Licenciatura & 108 \\
\hline Total & 1.227 \\
\hline
\end{tabular}

Fonte: Secretaria Geral dos Cursos - Campus Cerro Largo.

Esses alunos são oriundos de mais de cem diferentes localidades. Embora os dados se apresentem bastante dispersos, como destacado na Figura 3. Somente no estado do Rio Grande do Sul são 77 municípios. Mais da metade das cidades pertencem à Região Funcional de Planejamento 7, que compreende os COREDES Celeiro, Missões, Fronteira Noroeste e Noroeste Colonial, as quais estão incluídas na região prioritária de atuação da UFFS, especialmente do Campus Cerro Largo. Essas cidades representam, por sua vez, mais de 95\% dos alunos. Aproximando um pouco mais, considerando apenas Cerro Largo e seu entorno, nos municípios do COREDE Missões, os estudantes são oriundos de 23 municípios, totalizando 978 alunos, quase $80 \%$ do total. 
Figura 3 - Procedência dos alunos - Campus Cerro Largo - 2016/1

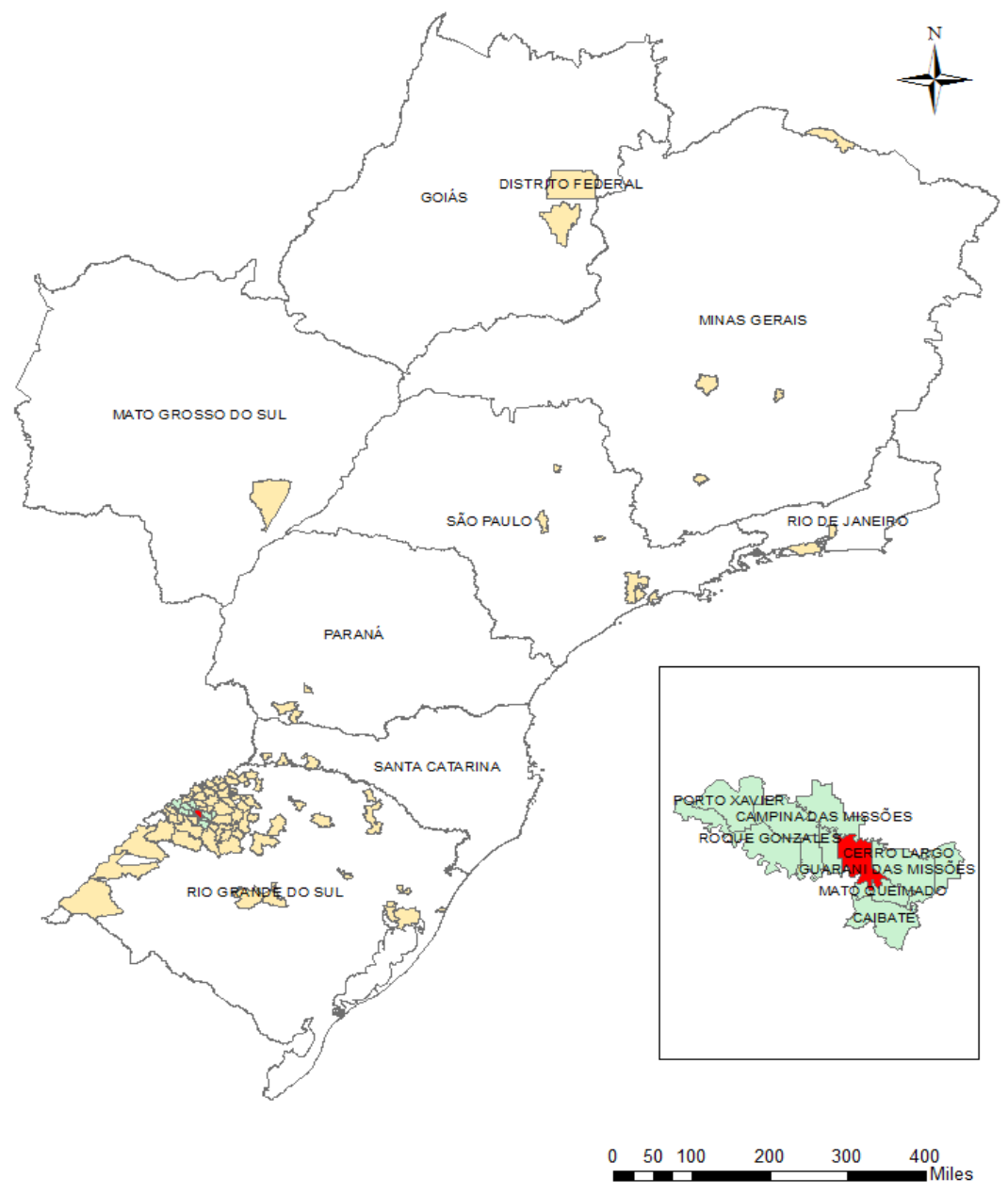

Fonte: Dados da Secretaria Geral dos Cursos - Campus Cerro Largo - elaborada pelos autores.

O Campus Cerro Largo oferece dois programas de Pós-Graduação Stricto Sensu. O primeiro, implantado em 2014, é o Mestrado em Desenvolvimento e Políticas Públicas. O segundo é o Mestrado em Ambiente e Tecnologias Sustentáveis. Ainda, de acordo com o Relatório de Gestão Pró-Tempore (2015), que abrange o período de 2010 a 2015, foram constituídos dez grupos de pesquisa certificados. Concederam-se 140 bolsas de iniciação científica e 131 bolsas para extensão. Também, considerando editais internos e de órgãos financiadores externos, o valor captado no campus é superior a R\$1.700.000,00. 


\section{OS REFLEXOS NO MUNICÍPIO DE CERRO LARGO}

Cerro Largo é um município com 177,674 km2, situado na região das Missões no Noroeste do Estado do Rio Grande do Sul, distante $498 \mathrm{~km}$ de Porto Alegre, capital gaúcha. Sua economia está baseada principalmente no setor de prestação de serviços, comércio, indústrias e setor agrícola com as culturas de soja, trigo, milho, além da suinocultura e gado de leite (Cerro Largo, 2016).

Florax (1992, apud TORRES et al., 2010) apresenta diversos efeitos externos à presença de uma universidade em um determinado território. Esses reflexos, para o autor, podem ser de ordem política, demográfica, econômica, de infraestrutura, cultural, educacional e social. Lopes (2003), por sua vez, define esses impactos como diretos e indiretos. Os primeiros estão relacionados aos investimentos em obras, equipamentos, infraestrutura e despesas de custeio da Instituição, aos gastos realizados por servidores docentes e servidores técnico-administrativos e às despesas dos alunos, principalmente aqueles oriundos de outros municípios. Já os impactos indiretos dizem respeito aos serviços prestados pela Universidade, principalmente os educacionais, à economia local pelos empregos indiretos gerados e pela disponibilidade de recursos humanos qualificados, formados pela instituição.

Alguns investimentos diretos podem ser facilmente quantificados. A aquisição de imóveis e a edificação da estrutura física exigiram consideráveis investimentos do governo federal a partir do ano de 2010. A Tabela 5 ilustra o volume desses recursos.

Tabela 5 - Investimentos na estrutura física - Campus Cerro Largo - 2010-2015

\begin{tabular}{l|l|l}
\hline Objeto & Ano de conclusão & Valor (em R\$) \\
\hline Aquisição Seminário São José & 2010 & $2.740 .000,00$ \\
\hline Reforma ginásio de esportes & 2011 & $612.773,55$ \\
\hline Reforma Seminário & 2013 & $845.829,76$ \\
\hline Bloco A & 2013 & $7.228 .145,06$ \\
\hline Laboratórios didáticos & 2013 & $7.922 .466,99$ \\
\hline Restaurante Universitário & 2014 & $5.180 .820,17$ \\
\hline Almoxarifado Central de Reagentes & 2014 & $231.088,53$ \\
\hline Galpão de maquinário agrícola & 2014 & $230.020,85$ \\
\hline Bloco de Professores & 2015 & $4.545 .000,00$ \\
\hline Infraestrutura & & $6.431 .843,32$ \\
\hline
\end{tabular}

Fonte: Santos (2015) - adaptada pelos autores. 
Mesmo considerando os valores históricos, sem qualquer atualização, a soma total ultrapassa, em cinco anos, 35 milhões de reais. Boa parte desses valores pode ter sido direcionada para outras regiões, em função das sedes das construtoras envolvidas e da aquisição dos insumos necessários. Por outro lado, a maior parte da mão de obra empregada nas edificações é radicada na região.

Dados obtidos no Portal da Transparência (2016) permitem estimar o valor mensal dos salários dos docentes e técnicos administrativos em $\mathrm{R} \$ 1.300 .000,00$. Esses recursos, ao ano, significam um valor próximo dos 18 milhões de reais injetados na economia regional. Segundo informações da Assessoria de Gestão de Pessoas do Campus Cerro Largo, vinculada à Pró-Reitoria de Gestão de Pessoas, além de Cerro Largo, muitos servidores residem em municípios próximos, como Guarani das Missões, Salvador das Missões, Santa Rosa, Santo Ângelo, São Luiz Gonzaga, Giruá, Cruz Alta, Ijuí, entre outros.

Algumas evidências de impactos ocasionados indiretamente podem ser apresentadas. Esses números, por certo, não se apresentam dessa forma apenas em função do campus. O PIB, por exemplo, divulgado pelo IBGE, passou de aproximadamente 274 milhões de reais, em 2009, para 590 milhões de reais em 2013. O valor bruto adicionado da agropecuária, da indústria e de serviços está na mesma direção, se comparados os valores dos anos de 2009 e 2013 . O primeiro passou de 28,5 milhões de reais para 40,5 milhões de reais. $O$ valor bruto adicionado da indústria foi de 36,2 milhões de reais para 48,4 milhões de reais. Por fim, o valor bruto adicionado referente aos serviços passou de 170 milhões de reais para 340 milhões de reais. A Fundação de Economia e Estatística, por meio do seu serviço on-line FEEDADOS (http://feedados.fee.tche.br) mostra o valor dos impostos arrecadados no mesmo período. Em 2009, o valor correspondeu a aproximadamente 39 milhões de reais enquanto que, em 2013, este valor foi de 110,5 milhões de reais.

Alguns indicadores são de difícil obtenção, como os relativos aos aspectos demográficos, de infraestrutura, políticos, culturais e sociais. Não existem informações demográficas além das relativas ao censo populacional de 2010. Mesmo as estimativas populacionais não são adequadas, pois não refletem os fenômenos específicos como é o caso da implantação de um campus universitário em tão curto espaço de tempo. 
Ainda na área econômica, a Confederação Nacional do Comércio (CNC), em 2016, apresenta dados referentes às empresas existentes em Cerro Largo, principalmente às micro e às pequenas empresas. Os 517 empreendimentos ativos no ano de 2009, dos quais 478 são micro e pequenas empresas (MPEs), passaram no ano de 2015, para 1.203, sendo 1.154 classificadas como MPEs. A Tabela 6 apresenta a distribuição das MPEs por ramo de atividade.

Tabela 6 - Micro e Pequenas Empresas - Cerro Largo - 2009-2015

\begin{tabular}{l|l|l}
\hline Ramo de atividade & 2009 & 2015 \\
\hline Comércio; reparação de veículos & 259 & 482 \\
\hline Indústria de transformação & 70 & 135 \\
\hline Alojamento e alimentação & 47 & 115 \\
\hline Transporte, armazenagem e correio & 33 & 74 \\
\hline Atividades profissionais, científicas e técnicas & 16 & 34 \\
\hline Outras atividades de serviços & 13 & 101 \\
\hline Construção & 9 & 115 \\
\hline Atividades administrativas e serviços complementares & 7 & 29 \\
\hline Educação & 6 & 22 \\
\hline Outros & 18 & 47 \\
\hline
\end{tabular}

Fonte: Confederação Nacional do Comércio (2016).

Por sua vez, as questões referentes às estruturas físicas mais importantes, em razão de que a maioria dos estudantes reside em municípios vizinhos, são aquelas que dizem respeito ao acesso a Cerro Largo. O transporte público dessas cidades para Cerro Largo é extremamente deficiente, pois são poucas empresas, linhas e horários disponíveis. Nesses seis anos de existência do campus, nenhuma mudança foi verificada em relação a isso.

Os aspectos políticos, culturais e sociais, por si só, não são quantificáveis. Contudo, esperam-se melhorias na organização dos processos políticos com o aumento da participação cidadã. Ambiciona-se também uma maior oferta $\mathrm{e}$ demanda de produtos e serviços culturais e que, finalmente, produzam efeitos sobre a qualidade de vida da população, sobre a imagem e identidade da localidade e da região. 


\section{CONSIDERAÇÕES FINAIS}

Avaliar a implantação de uma instituição de ensino superior, como de qualquer outra organização, é uma tarefa complexa. Em primeiro lugar, porque nem todos os reflexos são mensuráveis. Há uma série de elementos envolvidos, principalmente os aspectos sociais e culturais, dos quais apenas se podem perceber as modificações ocorridas. A realização de um trabalho de investigação com metodologia diversa poderia apresentar de maneira mais categórica tais mudanças.

O período em que se realizou esta avaliação é um período muito curto. Muitas informações, como o número de habitantes, que poderiam evidenciar o poder de atração da Universidade não foram ainda produzidas. Somente com o próximo Censo Populacional, em 2020, esta informação poderá ser obtida. Assim, neste capítulo, foram apresentados indicadores cuja série envolve um menor período de tempo, os quais, na sua grande maioria, evidenciaram uma significativa melhoria, ou crescimento, do município de Cerro Largo. Como já mencionado, a instalação de um empreendimento não é, necessariamente, a causa definitiva do crescimento de uma localidade, contudo contribui decisivamente para isso. Da mesma forma, não há como comparar o mesmo local com e sem essa instituição, no mesmo período de tempo.

Certamente os principais objetivos buscados, quando da criação e instalação de instituições públicas de ensino superior, não são os de ordem econômica. As atividades de ensino, pesquisa e extensão, voltadas à formação de capital humano na região são, possivelmente, o maior benefício que a Universidade Federal da Fronteira Sul - Campus Cerro Largo pode proporcionar. Os sete cursos de graduação, com suas 300 vagas anuais, já formaram suas primeiras turmas. Conforme mostrado anteriormente, a origem desses alunos é predominantemente da região e é admissível que se presuma que nela permaneçam. Cabe lembrar que quatro desses cursos são de licenciatura, quase não contemplados nas instituições de ensino superior privadas.

Houve, nos últimos dez anos, um incremento considerável da oferta de vagas no ensino superior para suprir uma crescente necessidade de alunos matriculados no ensino superior público e privado no país. Como estratégias principais do governo para permitir o acesso, a expansão e a equidade no ensino superior, destacam-se algumas ações e programas como o Programa Universidade para 
Todos (PROUNI) e o Programa de Apoio a Planos de Reestruturação e Expansão da Rede Pública Federal (REUNI). Esses programas, aliados a políticas de democratização de acesso e condições de permanência no ensino superior, ocasionaram, ao menos na UFFS, um contexto em que mais de $90 \%$ de seus alunos são oriundos de escolas públicas. Vale destacar que a maioria deles representa o primeiro membro da família a cursar o ensino superior.

\section{REFERENCIAS}

BRASIL. Lei $\mathrm{n}^{\circ} 10.172$, de 9 de janeiro de 2001. Aprova o Plano Nacional de Educação e dá outras providências. Brasília: Diário Oficial da União, 2001. . Lei $\mathrm{n}^{\circ} 11.892$, de 29 de dezembro de 2008. Institui a Rede Federal de Educação Profissional, Científica e Tecnológica, cria os Institutos Federais de Educação, Ciência e Tecnologia, e dá outras providências. Brasília: Diário Oficial da União, 2008. . Lei $\mathrm{n}^{\circ} 12.029$, de 15 de setembro de 2009. Institui a Universidade Federal da Fronteira Sul - UFFS. Brasília: Diário Oficial da União, 2009. INEP. Ministério da Educação. Censo da Educação Superior. Brasília: INEP, 2014.

. MEC. Ministério da Educação. Ministério da Educação. 2016. Disponível em: http://portal.mec.gov.br/. Acesso em: 31 jul. 2016. . MEC. Ministério da Educação. Portal da Rede Federal de Educação Profissional, Científica e Tecnológica. 2016a.Disponível em: http:// redefederal.mec.gov.br/. Acesso em: 31 jul. 2016.

. Governo Federal. Portal da Transparência. 2016. Disponível em: http://portaltransparencia.gov.br/. Acesso em: 31 jul. 2016.

BRITO, Leonardo Chagas de. A importância dos estudos sobre interiorização da universidade e reestruturação territorial. Espaço e Economia: Revista Brasileira de Geografia Econômica, São Gonçalo, RJ, v. 4, n. 4, p.1-15, nov. 2014. Disponível em: http://espacoeconomia.revues.org/802. Acesso em: 31 jul. 2016.

CEPAL. Panorama del desarrollo territorial en América Latina y el Caribe, 2015: Pactos para la igualdad territorial. Santiago de Chile: Cepal, 2015. 127 p. 
CERRO LARGO. PREFEITURA MUNICIPAL. Prefeitura Municipal de Cerro Largo. 2016. Disponível em: http://cerrolargo.rs.gov.br. Acesso em: 31 jul. 2016.

COSTA, Danilo M.; COSTA, Alexandre M.; AMANTE, Claudio J.; SILVA, Claudio H. P. Aspectos da Reestruturação das Universidades Federais por meio do REUNI - Um estudo no Estado de Santa Catarina. Rev. GUAL. Edição Especial, p. 01-24, Florianópolis, 2011.

DURHAM, E. O ensino superior na América Latina: tradições e tendências. Novos Estudos Cebrap, São Paulo, julho 1998, p. 92.

IBGE. Estatísticas do Século XX. 2003. Disponível em: http://seculoxx.ibge. gov.br/. Acesso em: 31 jul. 2016.

LOPES, Roberto Paulo Machado. Universidade Pública e Desenvolvimento Local: Uma abordagem a partir dos gastos da Universidade Estadual do Sudoeste da Bahia. 2001. 149 f. Dissertação (Mestrado) - Curso de Mestrado em Economia, Universidade Federal da Bahia, Salvador, 2001.

MANZANAL, Mabel. Desigualdade e desenvolvimento na América Latina: Conceitos e realidades opostas ou complementares? Geo UFRJ, Rio de Janeiro, v. 2, n. 23, p. 717-745, dez. 2012. Semestral.

MESOMERCOSUL: Federalismo, cooperativismo e organização social para o desenvolvimento. 2016. Disponível em: http://www.mesomercosul.org.br/. Acesso em: 31 jul. 2016.

PEREIRA, Thiago Ingrassia. A expansão do Ensino Superior no Brasil e suas Contradições: o caso da Universidade Federal da Fronteira SUL (UFFS). GT 25: Educación y desigualdad social, 2014. Disponível em: http://actacientifica. servicioit.cl/biblioteca/gt/GT25/GT25_IngrassiaPereira.pdf.

SAMPAIO, Helena. Evolução do ensino superior brasileiro, 1808-1990.

Núcleo de Pesquisas Sobre Ensino Superior da Universidade de São Paulo, São Paulo, v. 1, n. 1, p. 1-32, ago. 1991.

SANTOS, Taíz Viviane dos. UNIVERSIDADE FEDERAL DA FRONTEIRA SUL - Campus CERRO LARGO: UM ESTUDO SOBRE AS PERSPECTIVAS DE SUA IMPLANTAÇÃO COMO ESTRATÉGIA DE DESENVOLVIMENTO REGIONAL.2015. 182 f. Dissertação (Mestrado) Curso de Curso de Pós-graduação Stricto Sensu Políticas Sociais e Dinâmicas Regionais, Universidade Comunitária da Região de Chapecó, Chapecó, 2015. TORRES, Teresa et al. El impacto de la universidad en el ámbito económico y del conocimiento. El caso de la universidad de Lleida. Regional And Sectorial Economic Studies, Lleida, v. 3, n. 10, p. 1-26, mar. 2010. 
UFFS. Decisão no $\mathbf{2} / \mathbf{2 0 1 4}$, de 25 de abril de 2014. Autoriza a alteração do texto do Histórico Institucional da UFFS constante dos projetos pedagógicos dos cursos de graduação. Conselho Universitário: Câmara de Graduação. Chapecó, SC, 25 abr. 2014.

Ministério da Educação. Relatório de Gestão do Exercício de 2015. Chapecó, SC: UFFS, 2015. 211 p. . Ministério da Educação. Relatório de Gestão Pró-Tempore. Chapecó, SC: UFFS, 2015. 211 p. 